\title{
Feminismos en el Chile Post-Dictadura: Hegemonías y marginalidades. ${ }^{1}$
}

\section{Feminisms in the Post-Dictatorship Chile: Hegemonies and marginalities.}

Nicole Forstenzer ${ }^{*}$

\begin{abstract}
Resumen
Este artículo propone un análisis del feminismo en Chile en los años 2000 y plantea la existencia de tres ramas distintas de feminismo en el Chile post-dictatorial. La diferenciación de estas corrientes, más allá de lo meramente táctico o estratégico, ha implicado posiciones políticas divergentes en estrecho vínculo con la institucionalización del género a lo largo de veinte años de gobierno concertacionista. El análisis se centra en los repertorios de acción de estas diferentes ramas poniendo de manifiesto las tensiones y relaciones de poder que atraviesan el activismo feminista, para finalmente examinar en forma tentativa la reciente reactivación de esta forma de acción colectiva en el marco doble de las luchas sociales que exigen mayor democracia y justicia social en un plano nacional por un lado y por otro del resurgimiento del activismo feminista global con el rechazo a la violencia sexista del "MeToo" o "YoTambién" o la lucha en Argentina por la legalización del aborto.
\end{abstract}

Palabras Clave: Feminismo, Género, Movimientos Sociales, Chile, \#MeToo, Mayo Feminista.

\footnotetext{
${ }^{1}$ Este artículo fue inicialmente una ponencia presentada en el Coloquio Chile Actual. Gobernar y Resistir en una Sociedad Neoliberal (Grenoble, Francia, septiembre 2013) con el título "Ser feminista en el Chile actual: ambigüedades y dilemas de las reivindicaciones de igualdad de género". El texto fue revisado y ampliado para abarcar las últimas evoluciones de los feminismos en Chile para este número de Punto Género. Quisiéramos agradecer aquí a Ixs organizadorxs del Coloquio por su amable autorización para la publicación de esta ponencia en una versión revisitada.

* Doctora en Sociología, Universidad Paris I - IEDES.
} 


\begin{abstract}
This paper analyzes Chilean feminism in the 2000s and argues that three branches of feminism coexist in post-dictatorship Chile. The differentiation between these branches goes beyond merely tactical or strategic discrepancies and involves fundamentally divergent political projects. This differentiation is closely linked to the institutionalization of gender policies by the center-left coalition in power between 1990 and 2010, the Concertación. The analysis discusses the different branch's collective action repertoires and highlights the tensions and power struggles in Chilean feminism. Lastly, the paper sets forth a tentative analysis of the recent rebirth of feminist activism in 2018, premised on the intersection of two framing contexts: the domestic struggles for greater democracy and social justice and the international feminist uprising against sexual violence and harassment with the MeToo phenomenon or the campaign to legalize abortion in Argentina.
\end{abstract}

Key Words: Feminism, Gender, Social Movements, Chile, \#MeToo.

Fecha de recepción: Mayo 2019

Fecha de aprobación: Junio 2019

\title{
Introducción
}

Este artículo propone un análisis del feminismo en Chile en los años 2000. Este periodo del feminismo chileno suele ser caracterizado como un repliegue comparado al movimiento de segunda ola de los años 1980, como un nuevo "silencio" feminista en referencia a la caracterización hecha por Julieta Kirkwood (1986) del periodo que siguió la primera ola y la obtención del derecho a voto. Además, se hace hincapié en la profesionalización y ONGeización del feminismo y en el declive de su capacidad activista. El "mayo feminista" del 2018 que culminó en una marcha multitudinaria para el 8 de marzo 2019 en Santiago pero también en Valparaíso y otras ciudades de Chile, parece indicar hoy una finalización del periodo anterior de "silencio" de la post-dictadura y la manifestación de una nueva fase de activismo feminista con voz y resonancia en Chile. Se propone una discusión acerca de esta reciente reactivación feminista en este texto, con la indicación de que ésta no puede ser más que un esbozo de reflexión, ya que se carece de material empírico y teórico para un análisis más completo. 
Esta contribución se basa en la investigación de terreno llevada a cabo para la tesis doctoral ${ }^{2}$ (Forstenzer, 2012) entre el año 2004 y el año 2009 en Valparaíso, que consistió en una participación activa y en una inmersión en las organizaciones feministas de la zona así como en instancias de coordinación regionales y nacionales. Esta metodología fue completada por entrevistas con feministas profesionalizadas en la capital y por el estudio de documentos gubernamentales e internacionales. Asimismo, presenta resultados publicados en distintas revistas como Lien social et Politiques (2012) o la Revue internationale de politique comparée (2013). Sin embargo, si bien el trabajo de tesis se caracterizó por un examen simultáneo del feminismo como movimiento social por un lado y de las políticas públicas de género por otro lado, buscando entender las luchas por la definición y la resignificación de la categoría política "mujeres" que surgen de la interacción de estos dos campos, aquí nos enfocamos exclusivamente al objeto "feminismo", dejando de lado la temática de acción pública de género para situarnos de lleno en el campo de la sociología de los movimientos sociales o de la acción colectiva.

Este estudio argumenta que en el Chile post-dictatorial no hay un "silencio feminista", ni una pluralidad diversa de grupos feministas coexistiendo en una demostración armoniosa de heterogeneidad (Ríos Tobar et al., 2003). Seguimos los análisis (Franceschet, 2005; Stoffel, 2007a) que apuntan a la existencia de tres ramas distintas de feminismo. En el marco de las interacciones entre estas ramas, buscaremos subrayar una diferenciación de estas corrientes que va más allá de lo meramente táctico o estratégico e implica posiciones políticas divergentes. En lo sustancial, estas divergencias están estrechamente ligadas a la institucionalización del género a lo largo de veinte años de gobierno concertacionista, pero con mayor visibilidad y determinación a partir de la elección de R. Lagos en 2000 y el gobierno de M. Bachelet. La cara más visible del feminismo ha sido sin lugar a dudas el feminismo «institucional», gozando en el periodo concertacionista de una relación de cercanía con las cúpulas políticas; sin embargo, existe también una corriente autónoma y, por otra parte, una nebulosa de organizaciones pequeñas que constituye un feminismo de la movilización social. El análisis se centrará primero en la génesis de estas ramas del feminismo en las negociaciones de la transición y la desarticulación del movimiento de mujeres y feminista en los años 1990. Luego, presentaremos los repertorios de acción de estas diferentes ramas, sus implicancias respectivas, poniendo de manifiesto las tensiones y relaciones de poder que atraviesan el paisaje del activismo feminista partiendo del caso específico de Valparaíso en la segunda mitad de los anos 2000. Por último, se examinará en forma tentativa la reciente reactivación de esta forma de acción colectiva y una redefinición de sus reivindicaciones (framing) en el marco doble (Muñoz-Saavedra, 2019, cf. discusión más abajo) de las luchas internacionales difundidas por las redes sociales de rechazo al acoso y a la violencia sexual y sexista (el \#MeToo, \#YoTambien, \#NiUnaMenos 0 \#VivasNosQuermos), por un lado, y de las luchas sociales en Chile que exigen mayor democracia y justicia social, por otro lado.

\footnotetext{
2 Tesis dirigida por Bruno Lautier, Universidad Paris I, en enero del 2011. Publicada en 2012: Nicole Forstenzer, Politiques de genre et féminisme dans le Chili de la post-dictature, 1990-2010, Paris: L'Harmattan, 2012, 268 p. Próxima publicación en Chile por LOM.
} 


\section{Negociaciones de la transición: desmovilización y divisiones feministas}

El movimiento de mujeres y feminista de los años 1980 es plural y heterogéneo. Sin embargo, está coordinado y unido en torno a un objetivo y reivindicaciones comunes. Cuando empiezan las negociaciones de la transición, a mediados de los años 1980, surgen divisiones que se van acentuando hasta finales de la década. Algunas feministas deciden darle la prioridad a la acción desde el Estado, en la política formal o la cooperación desde la sociedad civil, mientras que otras consideran, al contrario, que es preciso constituirse en fuerza de presión autónoma. Luego, frente a la institucionalización a la vez prudente y selectiva de las reivindicaciones de igualdad entre mujeres y hombres por el Estado, el movimiento feminista inicia una reconfiguración profunda de sus posicionamientos y de sus repertorios de acción.

A fines de los años 1980, el movimiento ya se enfrenta con el tema de la doble militancia. En efecto, muchas feministas de la segunda ola son militantes de la Unidad Popular - fueron detenidas, torturadas y a menudo exiliadas. En el exilio, conocieron las segundas olas feministas de América del norte y Europa. De vuelta en Chile, las retornadas crean grupos y colectivos feministas en las que buscan concientizar a otras mujeres y en donde hacen un examen crítico de su participación política antes del golpe. En el vacío dejado por la represión a los partidos de izquierda y la eliminación muchas veces literal de sus dirigentes, el movimiento de mujeres y feminista, como otros actores sociales (secundarios, estudiantes, sindicatos) encuentra un espacio para organizarse y formular reivindicaciones en las protestas y la lucha para derrocar la dictadura. Sin embargo, cuando se recomponen los partidos y empiezan las negociaciones de la transición, las lealtades y pertenencias partidarias reaparecen dentro del feminismo, dando lugar a discusiones acaloradas (Kirkwood, 1986: 196-197). Las militantes de los partidos de la Concertación se agrupan dentro de una plataforma femenina de la Concertación, la Concertación de Mujeres por la Democracia, y tratan de posicionar sus demandas con las cúpulas partidarias ${ }^{3}$. Al mismo tiempo, las militantes de los partidos que no participan de una transición que juzgan injustamente pactada, como el Partido Comunista o el MIR, rehúsan prestarse al juego de la "lista de pedidos". Otras consideran que el movimiento feminista debe justamente ganar fuerza manteniéndose independiente y preservándose de intentos de cooptación por parte de un orden político fundamentalmente patriarcal.

Esta división se profundiza, para transformarse en una brecha insuperable en los primeros años de transición, en especial tratándose de las relaciones con las iniciativas del Estado en cuanto a igualdad entre mujeres y hombres. La intervención de un actor mayor obliga a nuevos posicionamientos, a la vez que abre a algunas la posibilidad de seguir trabajando desde la administración del Estado. De ahora en adelante, las feministas son invitadas a participar, junto al Estado, en la acción pública naciente, ya sea desde la administración o la "sociedad civil", aportando con su experticia. No obstante, esta nueva concepción de las relaciones entre feministas y Estado sólo está dirigida a las

\footnotetext{
${ }^{3}$ También hubo Demandas de las mujeres a la democracia, expresadas en 1988 por el grupo Movimiento Feminista.
} 
mujeres educadas de clase media, militantes o simpatizantes de los partidos políticos de la Concertación. Las feministas "populares" (según su propia denominación) y las mujeres organizadas en torno a la supervivencia en las poblaciones, se desmovilizan rápidamente, con cierta amargura frente al desfase entre sus expectativas - de participación política, económica y social - y la calidad de la democracia reinstaurada (Adams, 2002).

Así, la evolución del movimiento feminista chileno en post-dictadura se caracteriza primero, por una desmovilización importante, que afecta no sólo el movimiento feminista sino el conjunto del movimiento de mujeres, tras la pérdida de la unidad construida en torno al objetivo común y a la fragmentación de los espacios abiertos para el ejercicio del militantismo. Además, la creación del Servicio Nacional de la Mujer, SERNAM, abre una posibilidad directa para algunas militantes de trabajar para los derechos de las mujeres dentro del Estado. En este contexto de institucionalización a nivel nacional - e internacional, desde hace ya unos años - de las reivindicaciones feministas, la experticia en temáticas de género absorbe el trabajo de numerosas feministas en ONGs, centros de estudio, instituciones y fundaciones, o centros de investigación universitarios (MarquesPereira, 2008; Stoffel, 2007a et 2007b).

La posición hegemónica en el periodo post-dictadura es la profesionalizacióninstitucionalización feminista y la cooperación en el marco del proyecto político de la Concertación. Las otras posiciones feministas y reivindicaciones de mujeres que cuestionan los fundamentos del acuerdo político de la post-dictadura, como el sistema capitalista neoliberal (reivindicaciones sociales y económicas), la ideología nacional (reivindicaciones de indígenas Mapuches, por ejemplo), o la heteronormatividad, son relegadas a los márgenes del espacio político (Richards, 2004; Schild, 1994 y 1998; Blofield \& Haas, 2005).

Frente a esta evolución y a la luz de la experiencia aún viva en las memorias militantes del movimiento de los años 1980, se reconoce como por sentido común la aparición de un nuevo "silencio feminista". Si bien es innegable que la segunda ola feminista chilena se ha acabado y que el periodo de reflujo empezó en un contexto en muchos aspectos característico del backlash (Faludi, 1993, para la situación en EE. UU a inicios de la década del 80), este diagnóstico debe ser discutido, ya que contribuye a opacar las evoluciones efectivas del feminismo en el periodo (Ríos Tobar et al., 2003). En efecto, este silencio no significa ausencia, y numerosos colectivos se crean y trabajan durante el periodo, en paralelo a las organizaciones de las institucionales. Los efectivos globales del feminismo en el periodo post-dictadura no son multitudinarios, pero existe una dinámica continua de creación y disolución de grupos activistas, a la vez que se mantienen organizaciones que desempeñan papeles claves. M. Ríos Tobar et al. (2003: 115 et seq.) identifican los diferentes grupos y organizaciones feministas que existen en Santiago y en regiones en los años 1990, en base a una tipología de seis estructuras (colectivos, coordinadoras, ONGs, redes, programas de estudios de género, medios de comunicación). Muestran la concentración de ONGs en Santiago y la proliferación de colectivos nuevos, más pequeños, a veces definidos por una característica adicional (feminismo lésbico, etc.) así como el declive organizacional a fines de los 1990. Más recientemente, el sitio web del Observatorio Género y Equidad proponía un repertorio de 
las organizaciones feministas chilenas ${ }^{4}$. A principios de los años 2000 , de manera general, Santiago concentra la mayor cantidad de organizaciones y casi todas son parte de la rama profesionalizada del feminismo. La principal organización representativa de la corriente autónoma, el Movimiento Rebelde del Afuera, también se encuentra en Santiago. La mayoría de los grupos feministas en regiones conforman la nebulosa de lo que llamo, siguiendo la idea de S. Stoffel del "[militantismo] realizado mediante la movilización social” (2007b: 324), el feminismo de la movilización social.

Se han propuesto diferentes tipologías de las corrientes o de los tipos de organizaciones constitutivos del feminismo chileno contemporáneo. Según M. Ríos Tobar et al. (2003 : 107-108), existen dos corrientes estratégicas en el feminismo chileno: por un lado el "movimientismo aislado", y por otro el "advocacy". Sus actividades se darían en forma paralela, sin contactos entre ambos corrientes. S. Franceschet $(2005: 143-146)$ plantea la existencia de tres tipos de militantismo feminista: el feminismo "profesionalizado", el feminismo "asociativo" y el feminismo "autónomo".

Si bien me parece que efectivamente hay un periodo de silencio feminista en la post-dictadura chilena, este se caracteriza más por un acallamiento de todos los proyectos políticos alternativos, que por una ausencia de actividad feminista. Además, la referencia idealizada al movimiento de los años 1980 impide un análisis de los cambios que se dieron dentro de los feminismos chilenos (Ríos Tobar et al., 2003). La polarización del debate sobre el conflicto entre autonomía e integración ha dejado en la sombra un sector significativo del feminismo chileno, el que designo, apoyándome en S. Stoffel (2007 b: 324), como el feminismo de la movilización social.

La dinámica de institucionalización-profesionalización feminista es, por mucho, el resultado de la llegada al poder de la coalición de centro-izquierda compuesta por partidos donde militan o militaban muchas feministas (Partido socialista, PPD). Cuando se recrean las estructuras gubernamentales democráticas, muchas feministas retoman la militancia partidaria para darle la prioridad a la reconstrucción democrática global. El caso chileno constituye así una ilustración particularmente reveladora de las relaciones complejas entre socialismo y feminismo, ya que durante los veinte años de gobierno de la Concertación esta situación de institucionalización del feminismo y de trabajo en la administración y la política formal por parte de militantes del PS y del PPD que participaron en la segunda ola feminista desemboca en el establecimiento de relaciones privilegiadas entre feministas que trabajan en la administración, la academia y las ONG (un "triángulo de terciopelo", según el concepto de A. Woodward, 2004) ${ }^{5}$.

\section{Feminismos plurales: hegemonía y marginalidades.}

\footnotetext{
4 Este mapa de organizaciones puede consultarse aquí: http://www.observatoriogeneroyliderazgo.cl/. Sin embargo, no está siempre actualizada.

5 Me parece que esta configuración no corresponde a un «feminismo de Estado» sino a un "empresariado público de género», cf. artículo de 2013 en la Revue internationale de politique comparée.
} 
La institucionalización de las reivindicaciones de igualdad entre hombres y mujeres en el marco de una transición democrática fuertemente constreñida, pero también en un contexto regional e internacional de promoción del género en cuanto categoría de acción pública (conferencias de la ONU, en especial Beijing en el 1995 y Plataformas de Acción) provoca un verdadero cisma en los feminismos latinoamericanos entre "institucionales" y "autónomas" 6 . Por un lado, las organizaciones y las militantes aceptan trabajar con los distintos niveles de gobernanza que se instituyen sobre el tema del género, en una relación de proposición más que de protesta; por otro lado los colectivos que rechazan la lógica del petitorio, el fraccionamiento temático, los llamados a proyectos y los financiamientos según términos determinados por instituciones.

A continuación se exponen los distintos repertorios de acción y registros de reivindicaciones.

La corriente más visible es sin lugar a dudas el feminismo profesionalizado, presente mediante ONGs y centros de estudios, a menudo especializados en temáticas particulares y concentrados en la capital. La opción de la institucionalizaciónprofesionalización manifiesta una voluntad clara de acompañar los procesos de implementación de las políticas públicas de género. Asimismo, la reorientación de los repertorios de acción de las feministas institucionales hacia la producción de experticia, el advocacy y el monitoreo, establece relaciones con las instituciones nacionales y las organizaciones internacionales que diseñan políticas de género (sobre feminismo latinoamericano: Cañas, 2003; Álvarez, 1998; sobre la transnacionalización del feminismo chileno institucionalizado: Araujo, 2008). Estas acciones requieren estructuras organizacionales, medios financieros y capacidades técnicas y políticas (Marques-Pereira, 2008; Spanou, 1991:184). Concretamente, en términos de proyecto político, implica aceptar las limitaciones inherentes al ejercicio democrático en este contexto postdictatorial. Se puede observar una des-radicalización de las feministas institucionales definida principalmente por la traducción de las reivindicaciones (y por lo tanto anteriormente por la elección realizada entre las diferentes reivindicaciones) en objetos de política pública (Spanou, 1991: 62-63). Esta des-radicalización es acentuada por el peso de los partidos de derecha en el sistema político-institucional, así como por la presencia del PDC en la Concertación.

La corriente autónoma es numéricamente minoritaria, ya que solo consta de unos cuantos colectivos de larga trayectoria. Sin embargo, su presencia en las discusiones sobre el estado del movimiento es clave. Esta corriente "autónoma", es decir las personas y los grupos que contribuyeron a fundar el movimiento feminista autónomo en Chile y en América latina (cf. $7^{\circ}$ Encuentro feminista latinoamericano en Cartagena, Chile, 1996), se propone profundizar la radicalidad - por un lado, frente a la institucionalización de parte del movimiento y al tipo de políticas públicas de género que se implementan, pero por otro

\footnotetext{
${ }^{6}$ En encuentro de Cartagena en Chile en 1996 marca un hito en la separación de aguas a nivel continental. Desde ese momento en adelante, se han organizado encuentros feministas autonomos en paralelo a los encuentros feministas regionales. Sobre el tema de la autonomía y la institucionalización, cf FORSTENZER N., «Une déradicalisation collective? Institutionnalisation et divisions du féminisme chilien», Lien social et Politiques, n 68, 2012, pp. 193-210.
} 
lado frente a la reivindicación de autonomía de los grupos y colectivos feministas de la movilización social. Así, las autónomas se niegan a trabajar con instituciones públicas u organizaciones internacionales sobre políticas de género, pero no se distancian de los debates feministas y siguen con su trabajo de concientización y de producción teórica feminista. Participan por ejemplo en el Encuentro Nacional Feminista de Olmué en 2005 (Forstenzer, 2012: 134) y dan seguimiento a las discusiones que se abren ahí en cuanto al estado del movimiento (Pisano, sin fecha). Su feminismo consiste en una puesta en tela de juicio completa del sistema patriarcal y el rechazo de avalarlo mediante cualquier acción. Critican también abiertamente el sistema capitalista neoliberal y sus consecuencias sobre las vidas cotidianas de las mujeres en Chile, en América Latina o el mundo. Esta autonomía se define como independencia completa (teórica, política, militante) y se manifiesta a través de una distancia reivindicada: el grupo autónomo chileno, liderado por Margarita Pisano, teórica latinoamericana reconocida de la autonomía, se llama ahora el Movimiento Rebelde del Afuera (Pisano, 2009: 3-5). Frente a una autonomía amenazada ella misma de cooptación, la radicalidad es llevada aún más lejos para significar el hecho de apartarse, de mantener una distancia crítica. Dado que la autonomía misma habría sido recuperada por el pensamiento único feminista, el feminismo radical de la diferencia (Franulic, 2009: 27) reniega de esta etiqueta para quedarse en el afuera.

Según las autónomas históricas y actuales, esta autonomía fue justamente pervertida por las "Nini" - ni institucionales ni autónomas -, es decir el grueso de las feministas que militan en colectivos no institucionales, que no perciben remuneración por su trabajo ni financiamiento significativo para sus actividades, pero que tampoco se sienten involucradas en una confrontación con las feministas institucionales o expresan un rechazo rotundo al trabajo con entidades públicas. Es el feminismo de la movilización social, que incluye a las organizaciones de mujeres movilizadas en base a identidades plurales - indígenas, lesbianas, populares, etc. Estos grupos se encuentran también en otras ciudades de Chile, como Valparaíso, lquique o Concepción. Estas organizaciones practican la autonomía en la medida en que son efectivamente independientes de instituciones públicas, de los partidos políticos, y de las otras ramas del feminismo. Su autonomía se enfoca menos en la producción y el posicionamiento teórico, que en mantener una actividad militante constante sobre temáticas relevantes. La radicalidad de sus demandas varía de un colectivo a otro. Cada colectivo define su propia posición frente a las políticas públicas de género, por ejemplo, al trabajo con instituciones públicas o con feministas más institucionales, así como la difusión de una lectura feminista en las instancias de reivindicación anti-sistémicas que apuntan también a cuestionar el neoliberalismo o la heteronormatividad, por ejemplo. Este sector del feminismo chileno incluye, por lo tanto, un espectro amplio de opciones políticas, desde las organizaciones tendientes a cierto grado de institucionalización (por la existencia de financiamientos o los métodos de acción), hasta colectivos que reivindican una autonomía total (autogestión, acciones más directas, etc.). Por esta razón, frente a la hegemonía del feminismo institucionalizado, el concepto de feminismo "disidente", de O. Curiel, S. Massonet y J. Falquet (2005), retomado por S. Stoffel (2007b: 328-329), permite designar adecuadamente ambas corrientes, la autonomía y la movilización social. 


\section{Relaciones entre feministas y con las instituciones: el caso del feminismo de la movilización social en Valparaíso a fines de los años 2000.}

Las feministas de la movilización social son también voces críticas de la configuración institucional del género. Sin embargo, por lo general estos grupos no rechazan por principio vincularse con instituciones y pueden colaborar puntualmente con ellas o recibir financiamiento para proyectos específicos. En Valparaíso, entre 2005 y 2009, estas relaciones son más bien virtuales o hipotéticas, ya que la Oficina regional del SERNAM, regularmente solicitada para eventos particulares (protestas, actos, conmemoraciones del 8 de marzo), no responde a las solicitudes. Del mismo modo, cuando el Consejo Nacional de la Cultura y las Artes invitó en el 2009 las organizaciones de mujeres y feministas a tener puestos con información en su jornada de conmemoración del 8 de marzo, el programa del evento ya estaba establecido en forma detallada y las modalidades de esta participación no dejaban espacio para el diálogo ${ }^{7}$. En general, las organizaciones de mujeres y feministas no son incluidas en las políticas de participación del SERNAM que se enfocan a las beneficiarias de los programas y proyectos o a dirigentes comunitarias (centros de madres o juntas de vecinos) ${ }^{8}$. Entre la experticia y la posición de beneficiaria, no existe espacio para la expresión de perspectivas críticas o la formulación de reivindicaciones, ni el reconocimiento de la acción colectiva que problematiza el género.

A estas relaciones, a menudo inexistentes y a veces conflictivas con las instituciones, hay que agregar las relaciones distantes y en ocasiones igualmente tensas con las feministas profesionalizadas de la capital ${ }^{9}$. Las coordinaciones son escasas y suelen depender de la agenda de las institucionales: así, un llamado a proyectos de una ONG de Santiago sobre el aborto terapéutico suscitó la controversia y la decisión de varios colectivos de la movilización social de no participar por la necesidad de reivindicar el derecho al aborto sin apellido, es decir sin condiciones restrictivas. Asimismo, en el 2009, el proyecto de línea telefónica de asistencia para mujeres que se auto-administran un aborto con misoprostol, basado en las recomendaciones de la OMS y su protocolo de uso y financiado por la ONG holandesa Women on Waves, une en el territorio nacional ONGs y colectivos feministas en una coordinadora llamada Red de Salud de las Mujeres Chile. Sin embargo, este proyecto sufre la partida de las institucionales cuando hay

\footnotetext{
7 Comunicación personal, intercambio de correos electrónicos entre el CNCA y diferentes grupos feministas a principios del 2009.

${ }^{8}$ Entrevista con una de las tres funcionarias de la Unidad de promoción de derechos y participación de la Oficina Regional del SERNAM en Valparaíso, el 19 de marzo del 2009, duración: 50 minutos.

9 En efecto, no hay feministas profesionalizadas en Valparaíso o Viña del Mar, aunque algunos colectivos tienen financiamientos para apoyo organizacional y/o la indemnización de una encargada.
} 
amenazas de juicios en contra de las portavoces y las locutoras por parte de las organizaciones pro-vida, de la iglesia católica y los partidos políticos de derecha ${ }^{10}$.

Estas organizaciones feministas están en una situación de impacto menor en el espacio público, en particular porque no tienen eco dentro de las instituciones o las feministas profesionalizadas. Sus actividades se articulan en base al calendario de movilizaciones marcado por las jornadas del 8 de marzo, del 25 de noviembre (Día internacional contra la violencia contra las mujeres), o el 28 de septiembre (Día por la despenalización del aborto en América latina y el Caribe). La participación en las movilizaciones en Valparaíso entre el 2005 y el 2009 subrayó cuánto, por un lado, este calendario permite mantener una dinámica en cuanto "movimiento" así como actividades regulares en el espacio público, pero también se revela como un esqueleto básico de reivindicaciones, impidiendo profundizar en las reivindicaciones o acciones más duraderas o más integrales de un punto de vista temático (Forstenzer, 2012a: 140-144). A diferencia de las feministas institucionales, sus repertorios de acción se acercan más al militantismo (protestas, campañas de información, peticiones) y buscan concientizar a la población más que tener una influencia directa en las políticas públicas, en una relación más horizontal con la sociedad que vertical con el Estado.

Por otra parte, si bien es cierto que ya no se puede hablar de "movimiento de mujeres" en el Chile actual, siguen existiendo organizaciones, la mayoría heredadas de la segunda ola de los años 1980, de feministas populares o pobladores organizadas. Otras aparecieron en reacción a la creación y a las políticas del SERNAM. Es el caso específico de las organizaciones de mujeres rurales e indígenas agrupadas en la Asociación Nacional de Mujeres Rurales e Indígenas. Estas organizaciones de mujeres populares urbanas o rurales e indígenas han intentado, desde la institucionalización del tema del género en el marco de la transición democrática chilena, exponer su perspectiva sobre el género y sus reivindicaciones frente a la acción pública en este campo, dirigiéndose al SERNAM. Han tratado de posicionarse como interlocutoras validas, además de beneficiarias o clientas-usuarias. Sus dificultades en alcanzar esta posición son expuestas por V. Schild $(1994 ; 1998)$ et P. Richards (2004) y revelan los límites impuestos a las políticas de igualdad de género, como los accesos diferenciados a las instituciones públicas y al poder en la enunciación y la representación de los intereses de "las mujeres".

\section{El "Mayo feminista" de 2018: nuevo auge del movimiento feminista chileno}

El movimiento feminista estudiantil que atravesó el país en la primera mitad de 2018, y las marchas masivas del 8 de marzo $2019^{11}$ en las grandes ciudades chilenas

10 Cf. En particular: «Fono Aborto» desata escándalo e indignación en organizaciones pro-vida», Publimetro, 5 de mayo del 2009. Datos obtenidos en la red (Publimetro): https://www.publimetro.cl/cl/nota/fono-aborto-desata-escandalo-e-indignacion-en-organizaciones-provida/bNQieC!523510/\%20[consultado\%20el\%2020\%20de\%20junio\%20del\%202009].// [consultado el 20 de junio del 2009].

11 Según las autoridades en Santiago marcharon 190.000 personas y según las organizadores 300.000, principalmente mujeres, por la Alameda. Fuente: 
constituyen un contraste sorprendente con el periodo de post-dictadura que se acaba de describir. ¿Cómo entender el salto desde un periodo de baja intensidad del feminismo, como de los demás movimientos sociales, en Chile, que fue largo, conflictivo, marcado por la dificultad en alzar las voces, hacia el gran estallido de las movilizaciones feministas del 2018? ¿Cómo explicar primero la activación del feminismo como modalidad de organización política por parte de las estudiantes, primero, y luego como explicar el eco de simpatía (e irritación e incomprensión de algunos sectores también) con el cual resonó en la sociedad chilena para concitar apoyo y participación masiva, como lo ilustró el 8 de marzo 2019? Las imágenes de mujeres copando y desbordando la Alameda, llenando las calles de Valparaíso, recuerdan inevitablemente las marchas masivas del 8 de marzo de los años 1980 y marcan en primer lugar por su imprevisibilidad.

Aún es temprano para someter esta nueva sublevación feminista al ojo científico del análisis minucioso, para tratar de descifrar, entender, clasificar e, ineluctablemente, fijar en un discurso un movimiento vivo y dinámico, polifónico y alegre, en busca de sus propias definiciones y expresiones. Más allá de la promesa de cambio social y político, lo que se ofrece a continuación constituye un gesto, a modo de esbozo, para poner de manifiesto el potencial heurístico de esta re-movilización.

Este potencial heurístico se sitúa a tres niveles: primero, tiene implicancias obvias para la periodización del feminismo chileno, con la pregunta de una nueva ola y por consiguiente su caracterización en términos de posicionamiento de un sujeto político "mujeres" y la exploración de sus reivindicaciones y repertorios de acción. Segundo, plantea una nueva oportunidad para explorar la relación entre el feminismo, la izquierda y los otros movimientos sociales en Chile, es decir el debate autonomía versus integración o la interseccionalidad del feminismo como movimiento social. Por último, esta nueva ola feminista en Chile se ofrece como prisma para abordar las evoluciones de la vida política chilena, con el debate de la periodización de la transición a la democracia para desdibujar un posible cierre del periodo postdictatorial.

Siguiendo los escasos estudios publicados hasta la fecha sobre este fenómeno ${ }^{12}$, se puede formular la hipótesis que el Mayo feminista se desenvuelve dentro de un marco doble, constituido por un lado por un nivel internacional caracterizado por una efervescencia feminista de denuncia del acoso y de las violencia sexuales, iniciado por el \#MeToo en EEUU y amplificado y desmultiplicado por sus expresiones locales, como por ejemplo \#YoTambien o \#NiUnaMenos. Este marco sería lo que constituye, según Judith Muñoz-Saavedra ${ }^{13}$, la cuarta ola feminista que nace del Sur global y se expresa mediante la utilización de las redes sociales, lo que facilita su expresión, difusión y recepción, mermando así la posición hegemónica del feminismo occidental blanco. Es interesante

\footnotetext{
https://www.elmostrador.cl/destacado/2019/03/08/desbordante-movilizacion-feminista-concentra-a-varioscientos-de-miles-de-personas-en-santiago-y-regiones/

Consultado el 12 de julio 2019. Valparaiso marcharon 10.000 personas, principalmente mujeres, fuente: $\quad$ https://www.soychile.cl/Valparaiso/Sociedad/2019/03/08/584759/Con-masiva-marchaconmemoraran-el-Dia-de-la-Mujer-en-Valparaiso.aspx Consultado el 12 de julio 2019.

12 En especial Zerán F. (2018), y Muñoz-Saavedra J. (2019).

13 Judith Muñoz-Saavedra es una miembra fundadora de la Colectiva Feminista Las Sueltas en la que milité en Valparaíso entre 2005 y 2009. En este periodo ella ya vivía en España.
} 
notar que este nivel internacional ha sido una constante de las olas feministas, que sea la primera en torno al sufragio o la segunda en torno a la politización de lo privado ${ }^{14}$.

El otro marco de la movilización feminista de 2018 se despliega a nivel nacional y constituye la serie de movilizaciones sociales desde el 2006 en adelante, constitutivas de lo que M. Doran $(2009,2010)$ llama el "rechazo de la impunidad". Esta serie de movilizaciones se conjuga con otra serie de cambios en el escenario político chileno: primero la alternancia política, con la llegada de la derecha al poder en 2010, y luego con una reconstitución paulatina del espectro de la política formal. En efecto, a partir del primer gobierno de S. Piñera, la Concertación se encuentra en tensión para luego desaparecer y reconstituirse como Nueva Mayoría (2013-2018), que incorpora el PC. El eje de esta coalición se desplaza hacia la izquierda, dando lugar a un reacomodo del centro hacia la derecha liberal. La izquierda llamada extraparlamentaria, nutrida de las y los dirigentes del movimiento estudiantil de 2011, adquiere mayor peso y entra a las instancias electivas (alcaldías de Valparaíso y Recoleta por ejemplo, en 2016 y 2012 respectivamente) así como al gobierno con el segundo mandato Bachelet de 2014 a 2018 (ministra del SERNAM y luego de la Mujer y de la Equidad de Género, Claudia Pascual, PC), terminando de sacudir un sistema político de post-dictadura basado en dos grandes bloques con un centro de gravedad de centro-derecha. Las reformas del sistema electoral del segundo gobierno de Bachelet, con el final del sistema binominal, la inscripción automática y el voto voluntario, el voto de las y los chilenos en el exterior, constituyen una apertura del espacio político formal. Sin embargo, estos cambios en el ámbito de la política formal representan más un reflejo o una incidencia de la agitación experimentada en las movilizaciones sociales, que un factor causante de ellas.

Así, si bien, como se notó más arriba, este "Mayo feminista", como se ha llamado en referencia al mayo de 1968, del cual se conmemoraba este año el 50 aniversario, es ante todo un recuerdo de la no linealidad de los movimientos sociales y de su imprevisibilidad. Esta agitación feminista constituye una culminación y una concretización inesperada de múltiples fenómenos precursores que venían remeciendo la sociedad chilena desde el 2006 y más marcadamente aun, desde el 2010. En una analogía con la cronología de activismos feministas descoloniales precursores del MeToo y del Mayo feminista que plantea Muñoz-Saavedra, se puede plantear un marco cronológico análogo para la re movilización social y el cambio en la percepción de la opinión de las nociones de justicia social, de indignación y de contestación. Esta cronología partiría con la revolución de los y las pingüinos.as del 2006, seguiría con la indignación y las protestas de rechazo a la decisión de 2008 del Tribunal Constitucional de prohibir la pastilla del día después y todos los métodos anticonceptivos constituidos de levornogestrel, por su carácter abortivo. El movimiento secundario y estudiantil del 2011 es un hito mayor, momento en que la opinión pública se vuelca hacia un apoyo masivo a la movilización de la juventud chilena que exige una educación gratuita y de calidad. Siguen una serie de luchas sociales y políticas desde la Araucanía y los y las Mapuches hasta un nuevo ciclo de luchas sindicales en distintos ámbitos, pasando por la entrada a la política formal de

\footnotetext{
14 No entraremos aquí en las consideraciones acerca de la existencia una tercera ola feminista. Para nuestro juicio, en Chile no ha habido, siendo el periodo postdictadura claramente un periodo de reflujo.
} 
líderes del movimiento de 2011 y la creación de nuevas agrupaciones políticas de izquierda y las marchas masivas por el aborto legal, seguro y gratuito en 2013.

En todas y cada una de estas movilizaciones, se despliega un cuestionamiento global al modelo de sociedad y de economía neoliberal heredado de la dictadura y mantenido a lo largo de la post-dictadura.

El petitorio del 8 de marzo 2019 en Chile es una ilustración de este "feminismo en clave descolonial" al cual apunta K. Oyarzun (2018), de esta interseccionalidad descrita por Muñoz-Saavedra, y de la "ruptura antineoliberal planteada" por N. Richard (2019), en breve, de la determinación del feminismo chileno contemporáneo de asumirse en la pluralidad de posicionamientos, pero con clara vocación de protagonismo político y de articulación de las luchas. 
1. Fin a la violencia política, sexual y económica hacia mujeres, disidencias sexuales, cuerpos racializados, migrantes y comunidades. Denunciamos la justicia patriarcal y racista. ¡No más femicidios en la impunidad!

2. Trabajo digno, estable y seguro para todxs. Fin a las AFP. Por un nuevo sistema de seguridad social, salud y cuidados. ¡Cuidar y criar también es trabajar!

3. DDHH y constitucional a la vivienda digna. Producción social del hábitat en manos de pobladoras y pobladores. Banco de suelos y movilidad.

4. Nueva ley de migración con enfoque de derechos y género. Libre organización y sindicalización de mujeres migrantes. Transversalizar el antirracismo en el feminismo.

5. Despenalización social del aborto. Derecho al aborto libre, legal, seguro y gratuito. Reconocimiento de derechos sexuales y reproductivos como $\mathrm{DDHH}$.

6. Justicia y verdad ante violaciones de DDHH que precarizan la vida. Construir memoria feministas, antirracista, antipatriarcal, anticolonial y anticapitalista como herramienta para las luchas y resistencias.

7. Derecho a la educación artística interdisciplinaria. Nuevo sistema de financiamiento público a cultura la cultura y las artes. Ley de medios en Chile con perspectiva feminista.

8. Fin al extractivismo: No más zonas de sacrificio. Soberanía y autodeterminación de pueblos y territorios en resistencia. Desmilitarización en Wallmapu. Justicia para macarena Valdés, Camilo Catrillanca y todxs los que luchan.

9. Activismo feminista y queer en todos los territorios. Reconocimiento social y tipificación de incitación y crímenes de odio. Programas educativos sobre disidencias sexuales y género en educación y salud pública y privada.

10. Educación como derecho social desmercantilizado. Modelo educativo democrático, no sexista, anticolonial y laico.

Fuente: Coordinadora Feminista 8 de marzo, 2019. 
Revista Punto Género № 11. Junio de 2019

ISSN 0719-0417 / 34 - 50

\section{Bibliografía}

Adams, Jacqueline (2002): "Gender and Social Movement Decline; Shantytown Women and the Prodemocracy movement in Pinochet's Chile", en Journal of Contemporary Ethnography, Vol. 31, n³, p. 285-322.

Álvarez, Sonia. (1998): El Estado del Movimiento y el Movimiento en el Estado. Accesible en el portal Agenda de las Mujeres, http://agendadelasmujeres. com. ar.

Araujo, Kathya (2008) : "Transnationalisation et politiques publiques; les processus d'institutionnalisation des agendas féministes", Science politique et actualité : l'actualité de la science politique. Communication au quatrième Congrès de l'ABSP-CF, Belgique, Louvain-la-Neuve, 24-25 avril.

Blofield, Merike \& Hass Liesl (2005): "Defining a Democracy: Reforming the Laws on Women's Rights in Chile, 1990-2002”, en Latin American Politics \& Society, Vol.47, No³, p. 35-68.

Cañas, Mercedes (2003) : "Le mouvement féministe et les institutions internationales", en Bisilliat, Jeanne (Dir) : Regards de femmes sur la globalisation, p. 129-151. Paris : Karthala.

Curiel,Ochy; Masson, Sabine; Falquet, Jules (2005): "Féminismes dissidents en Amérique latine et aux Caraïbes”, en Nouvelles Questions Féministes, Vol. 24, No 2. En la red: http://www.unil.ch/webdav/site/liege/shared/NQF/24 2/EditoNQF24-2OK.pdf

Doran, Marie-Christine (2010) : "Les femmes et la politique au Chili : la dynamique et l'impact de l'accession au pouvoir de Michelle Bachelet", en Recherches féministes, Vol. 23, No 1, p. 9-27.

Doran: Marie-Christine. (2009) : "Les dimensions politiques de la souffrance au Chili (1998-2007)", en Borgeaud-Garciandia, Lautier, Peñafiel y Tizziani (Dir) : Penser le politique en Amérique latine, p. 129-148. Paris, Karthala.

Faludi, Susan (1993) : Backlash; La guerre froide contre les femmes. Paris: Des femmes.

Forstenzer N. (2013) : "Représenter les intérêts des femmes dans le Chili de la postdictature: enjeux et conflits" en Revue internationale de politique comparée, vol. $20, \mathrm{n}^{\circ} 1$, pp. 25-45.

Forstenzer, Nicole (2012a) : "Une déradicalisation collective? Institutionnalisation et divisions du féminisme chilien” en Lien Social et Politiques, n68, pp. 193-210.

Forstenzer, Nicole (2012b) : Politiques de genre et féminisme dans le Chili de la post- 
Revista Punto Género № 11. Junio de 2019

ISSN 0719-0417 / 34 - 50

dictature, 1990-2010. Paris: L'Harmattan.

Franceschet, Susan. (2005): Women and Politics in Chile, Boulder/London: Lynne Rienner Publishers.

Franulic, Andrea (2009): "Cuando decimos autonomía, sabemos de lo que estamos hablando" en Feminismos Cómplices 16 Años Después, Mexico, Feminismos Cómplices/Taller Editorial La Correa Feminista/CICAM, p. 25-33. En la Red: http://www.americalatinagenera.org/biblioteca/detalle.php?IDPublicacion=781.

Kirkwood, Julieta (1986): Ser política en Chile. Las feministas y los partidos. Chile: FLACSO.

Marques-Pereira, Bérengère. (2008): "L'accès des femmes à l'espace public : du local au national, de l'international au transnational ; l'exercice de la responsabilité publique et les rapports de genre en Amérique latine", en Nuevo Mundo Mundos Nuevos [On line]. Disponible en: http://nuevomundo.revues.org/index34293.html

Muñoz-Saavedra, Judith. "Una nueva ola de feminista... más allá de \#MeToo. Irrupción, legado y desafíos". En P. Rivera-Vargas, J. Muñoz-Saavedra, R. Morales Olivares y S. Butendieck-Hijerra (Ed.): Políticas Públicas para la Equidad vol II. [Preprint] 2019. Santiago de Chile: Colección Políticas Públicas, Universidad de Santiago de Chile.

Oyarzún Kemy (2018): Mayo 2018: feminismos en clave descolonial. ZERÁN Faride (ed.). Mayo Feminista. La rebelión contra el patriarcado. Santiago. LOM, 2018, pp. 99-113. (Feminismos y géneros, Ciencias sociales y humanas).

Pisano Margarita (2009): "Fracasos y una salida", en Feminismos Cómplices 16 Años Después. México: Feminismos Cómplices/Taller Editorial La Correa Feminista/CICAM, p. 3-5. En la red: http://www.americalatinagenera.org/biblioteca/detalle.php?IDPublicacion=781

Richard, Nelly (2018): “La insurgencia feminista de mayo 2018” en Zerán, Faride (Ed.). Mayo Feminista. La rebelión contra el patriarcado. Santiago, p. 115-135. Chile: LOM.

Richards, Patricia (2004): Pobladoras, Indígenas and the State. Conflicts over Women's Rights in Chile, New Brunswick. New Jersey/London: Rutgers University Press.

Ríos Tobar, Marcela; Godoy Catalán, Lorena; Guerrero Caviedes, Elizabeth. (2003): ¿Un nuevo silencio feminista? La transformación de un movimiento social en el Chile posdictadura. Santiago: Centro de Estudios de la Mujer/Editorial Cuarto Propio.

Ríos Tobar M. (1997), "Institucionalización de las políticas de género y consolidación democrática: la experiencia chilena", en Latin American Studies Association Congress, Guadalajara, México. En la red: http://lasa.international.pitt.edu/LASA97/riostobar.pdf 
Revista Punto Género № 11. Junio de 2019

ISSN 0719-0417 / 34 - 50

Datos obtenidos el 26/09/09.

Schild, Verónica (1998): "Market Citizenship and the "New Democracies": the Ambiguous Legacies of Contemporary Chilean Women's Movements", en Social Politics, Vol. 5, No 2, pp. 232-249.

Schild, Veronica (1994) "Recasting "Popular" Movements: Gender and Political Learning in Neighborhood Organizations in Chile”, en Latin American Perspectives, Vol.21, No², p. 59-80.

Spanou, Calliope. (1991) : Fonctionnaires et militants : étude des rapports entre l'administration et les nouveaux mouvements sociaux. Paris : Editions L'Harmattan.

Stoffel, Sophie. (2007a) : "Pratiques et stratégies pour un meilleur accès des femmes à la cité: considérations à partir du cas chilien”, en Jenson, Marques-Pereira y Remacle (dir.): L'Etat des citoyennetés en Europe et dans les Amériques, p. 317-334. Montréal : Presses de l'Université de Montréal

Stoffel, Sophie (2007b): "L'institutionnalisation au service de l'autonomie des féministes chiliennes", en Recherches féministes, Vol. 20, No. 2, p. 37-59.

Woodward, Alison (2004): "Building Velvet Triangles: Gender and Informal Governance". En Piattoni Simona y Christiansen Thomas (Eds): Informal Governance and the European Union, p. 76-93, Londres: Edward Elgar Publishing.

Zerán, Faride (Ed.). (2018): Mayo Feminista. La rebelión contra el patriarcado. Santiago:LOM. 